Marina Braun-Unkhoff, Trupti Kathrotia, Bastian Rauch, Uwe Riedel

About the Interaction between Composition and Performance of Alternative Jet Fuels

CEAS Aeronautical Journal 7 (2016) 83-94

The original publication is available at www.springerlink.com

http://dx.doi.org/10.1007/s13272-015-0178-8 


\title{
About the Interaction between Composition and Performance of Alternative Jet Fuels
}

\author{
Marina Braun-Unkhoff*, Trupti Kathrotia ${ }^{\ddagger}$, Bastian Rauch ${ }^{\ddagger}$, Uwe Riedel \\ Institute of Combustion Technology, German Aerospace Center (DLR) \\ Pfaffenwaldring 38-40, 70569 Stuttgart, Germany \\ ¥: Institute of Combustion Technology for Aerospace Engineering, Stuttgart University \\ Pfaffenwaldring 38-40, 70569 Stuttgart, Germany \\ *: Corresponding author: marina.braun-unkhoff@dlr.de, phone: +49-711-6862-508 ; fax: +49-711-6862-578
}

\begin{abstract}
Since the last decade, the aviation sector is looking for alternatives to kerosene derived from crude oil triggered also by commitments and policy packages, such as the 'Flightpath 2050' initiative and the comprehensive alternative fuels strategy, both released by the European Commission. An aircraft need with regard to a fuel is very strict, with severe constraints to ensure a safe and reliable operation for the whole flight envelope. When synthesizing a jet fuel from scratch, two important aspects need to be addressed: First, the safety aspect - the new fuel candidate must be certified, qualifying through several well-defined cost and time expensive tests, according to the approval protocol; secondly, the environmental aspect. Alternative aviation fuels alike Jet A-1 are composed of hydrocarbons; however, amount and type of hydrocarbons (chemical family) differ considerably. The question is how the composition of the fuel will affect its suitability and performance: (i) thermophysical and thermo-chemical properties of the new components to exclude any shortcomings with respect to performance and safety issues, and (ii) the new fuel combustion characteristics, i.e. ignition, flame speed, and emission pattern (pollutants), in particular. These issues are addressed in the present study. Thus, the road will be paved for developing a generalize science based tool to investigate in an efficient way if a new fuel candidate may meet the fuel specifications.
\end{abstract}

Keywords Alternative Aviation Fuels - Combustion Molecular Properties - Modelling - Ignition - Laminar Flame Speed

\section{Introduction}

The increased worldwide interest in the exploration of alternative energy resources is a direct response to the increased awareness of the problems occurring when burning fossil fuels [1-2]. As far as aircraft industry is involved, these concerns have triggered the struggle for the identification and evaluation of alternative aviation fuels, i.e. non-crude oil based kerosene, with a preference on sustainable fuels [3-9].

Recently, the European Commission (EC) has published its vision of clean power for transport describing in detail the European comprehensive alternative fuels strategy. Within its paper, the effect of the oil dependency on the European economy was stated too large to neglect - and the need was expressed to act to end it. The EC sets out a comprehensive alternative fuels strategy, aiming at establishing a long-term policy framework, to guide technological development.

As there is no single fuel solution for the future of mobility, many alternative fuel options must be pursued. For aviation fuels, limited alternatives are available because aircraft needs are very specific, with severe constraints on e.g. freezing point, energy density, and further physical and chemical properties. This is addressed by the need for the specification and approval of any aviation fuel, to ensure a safe and reliable operation for the whole flight envelope [10-11].

Within this context, biofuels are important alternative fuels, because they can be produced from a wide range of feedstock through technologies in constant evolution and used directly or blended with conventional fossil fuels. For aviation, advanced biofuels are the only low- $\mathrm{CO}_{2}$ option for substituting kerosene.

As an example, the 'Flightpath 2050' EC-initiative [12] aims at a $75 \%$ reduction in $\mathrm{CO}_{2}$ emissions and $90 \%$ reduction in nitrogen oxide (NOx) emissions. In the U.S., several initiatives are ongoing, see e.g. the "Commercial Aviation Alternative Fuels Initiative” (CAAFI) [3].

Presently, a wide range of possible fuel candidates and fuel blends are discussed, resulting so far in the approval of three classes of sustainable alternative jet fuels [13-15]. The composition of alternative aviation fuels is similar to the one of Jet A-1 as they also consist of hydrocarbons. However, amount and type of hydrocarbons (different chemical families) might differ considerably.

It is an open question how the chemical nature of $e . g$. a fuel or a fuel candidate will affect its suitability and performance. First, thermo-physical and thermo-chemical properties of the components and of the fuel blends need to be carefully investigated to exclude any failures with respect to performance and safety issues. Secondly, the fuels combustion characteristics need to be investigated, such as autoignition and flame speed to ensure the fuel's suitability and applicability.

Hence, a comprehensive knowledge of the properties of synthetic jet fuels is needed, by a combined effort of computational fluid dynamics modeling and experimental characterization, such as determining major combustion properties e.g. ignition delay time and laminar flame 
speed. Thus, a more efficient and optimized use of synthetic fuels in aero-engines [16-21] can be achieved.

In the present work, selected properties of the components a jet fuel might be comprised of are collected, as a pre-requisite to be able to work on the development of modeling tools that will contribute to a prediction of the performance of a synthetic fuel and the detailed processes that occur during the fuel's placement (thermo-physical properties) and the fuel's combustion (chemical properties).

This paper is part of on-going work [22] on how to address these issues efficiently in a comprehensive way. Numerical methods, with their performance validated by relevant experiments, are part of the study, in addition to experimental investigations, mostly due to the variety of synthetic jet fuels, engines, and parameters.

The ultimate goal is to cover the chain from fuel composition to fuel properties and combustion performance, of available and candidate alternative fuels to enable a comprehensive numerical investigation of the combustion of a fuel (Fig. 1).

Thus, the road will be paved for contributing to developing a more general and more scientific based tool to investigate in an efficient way if any new fuel candidate may meet the required fuel specifications.

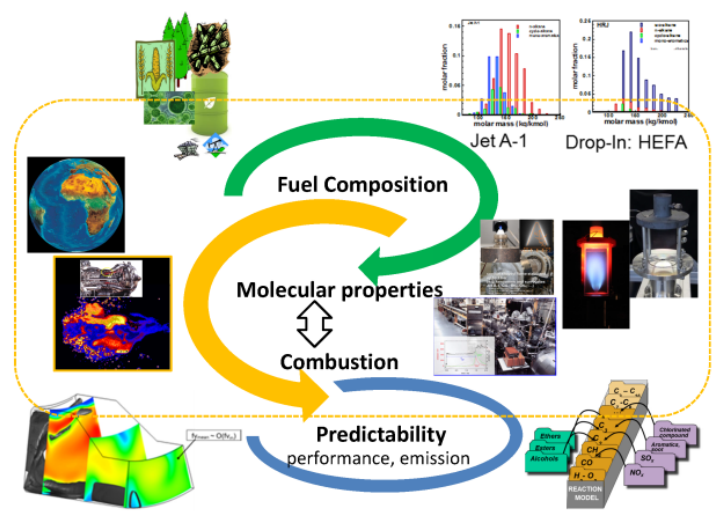

Fig. 1: The interaction between fuel's composition and fuel's performance, focusing on combustion aspects

\section{Background on aviation jet fuels}

Any aviation fuel must be certified and approved, for safety reasons and to guarantee an optimized operation, also with respect to the fuel distribution, worldwide. Thus, the aviation fuel is expected to perform properly with respect to the combustion in the aero engine and to the whole fueling system including material (sealing) and thermo stability aspects of the fuel itself.

In addition to these requirements, further constraints exist for alternative jet fuels, determining their short-tomidterm acceptance by the customers. Alternative fuels must be compatible (drop-in fuel) or at least almost compatible (near drop-in fuel) to today's aircrafts, mostly for cost reasons. Hence, all alternative fuels are liquids; only those alternative fuels will be viable, whose properties are at least as good as those of Jet A-1.
In this context, sustainable aviation fuels (biofuels) are of advantage with respect to the environment due to their reduced lifecycle $\mathrm{CO}_{2}$ emissions, of up to $80 \%$ if produced from renewable resources [23]. The availability of sustainable alternative aviation fuels (mainly in large scale production processes and most important in yield) were identified as the bottleneck in introducing sustainable biofuels, together with issues of biomass availability and economic feasibility of scaling-up the production capabilities [6]. Thus, the search is on for finding sustainable drop-in fuels that can be produced in commercial quantities, without competing with food crops and water supplies.

Presently, a large variety of feedstock, processes, and resulting products are discussed; see e.g. [12, 24-26]. Several steps must be approved when developing and introducing a new synthetic aviation fuel, with identification of feedstock and process as well as characterization and approval of fuel among them [2627]. To facilitate the development and deployment of promising alternative fuels, a way to classify and track progress on research, certification, and demonstration activities is needed.

\subsection{Guidance for aviation jet fuels}

As a response to this need, CAAFI developed several documents: (i) The "Path to Alternative Jet Fuel Readiness" - to outline the process of fuel development, qualification, and certification interested in producing alternative fuels [28]; (ii) The "Path to Fuel Readiness" describing how to become involved with the aviation community, the testing and environmental evaluations required to show the fuel's suitability for aviation use, and how to best facilitate ASTM International certification for a new fuel [29-30].

CAAFI also introduced two scales: (i) the fuel readiness level (FRL), as a measure for the technical feasibility of a potential aviation fuel by assessing fuel quality from the certification, following the approval process; (ii) the feedstock readiness level (FSRL) to track development and availability of the raw materials (or feedstock) required to make alternative jet fuels.

These documents serve as a roadmap for potential producers and other supply-chain participants contemplating purchase agreements with airlines for nonpetroleum-derived jet fuels. The roadmaps and milestone databases developed and maintained by CAAFI use the FRL classification to help organize and track the research and development milestones and the process of developing, certifying, and supplying alternative fuels to commercial aviation [31].

\subsection{Specification of aviation jet fuels}

Only a certified fuel is allowed to be used for commercial flights. The kerosene-type of fuel used in aeronautics is not solely the energy carrier but is also a major 
component in heat exchange and weight balance, all of this under very extreme conditions ranging from ground conditions to high altitude.

For these reasons, kerosene is the only practical fuel produced under very strict physical standards (energy content, freezing point, boiling point, viscosity, surface tension, minimum ignition temperature, etc.) in order to cope with the demands of civil and military aviation.

The two specifications primarily used worldwide for aviation gas turbine fuels are ASTM D1655-14a [10] and Def Stan 91-91 [11]

Concerning alternative aviation fuels, two further specifications were elaborated: (i) ASTM D4054 standard practices for qualification and approval of new aviation turbine fuels and fuel additives; and (ii) ASTM D7566 - standard specification for aviation turbine fuels containing synthesized hydrocarbons. An alternative aviation fuel usually has to be blended with Jet A-1, with up to $50 \%$ maximum, depending on the type of alternative fuel (see Table 1).

Note that within this certification process, numerous tests must be performed before a fuel candidate is approved for use [26-28]. Fuel specification and so-called fit-to-purpose properties tests are scheduled, with e.g. determining bulk physical properties such as density vs. temperature and ground handling aspects, with e.g. flammability limits and autoignition temperature, besides others [27]. Running all these tests according to the approval protocol is a time- and cost consuming process.

\subsection{Current alternative aviation jet fuels - Overview}

Synthetic fuels can be obtained from fossil (coal, gas) and renewable sources (waste, biomass) by many pathways: via (i) gasification applying the Fischer-Tropsch (FT) process; (ii) liquefaction or pyrolysis; (iii) biological or chemical pathways; (iv) hydrolysis and/or fermentation; and (v) hydrogenolysis and esterification, once oil is extracted. For information on alternative aviation fuel tests including jet fuel candidates, see [10, 26].

Today, the technical feasibility of alternative jet fuels is proven [19, 24-26]. For a table of alternative fuel tests, see [19-21, 25, 32-33]; for an overview of commercial flights with biofuels that have taken place so far, see [34].

A summary of alternative aviation fuels certified and approved so far is given in Table 1. A CtL (Coal-to Liquid), developed by SASOL was the first alternative jet fuel approved for commercial aviation; the farnesane, to be blended up to $10 \%$ with Jet A-1, developed by Amyris/Total applying a process named "Direct Sugar to Hydro Carbon (DSHC)" was the most recent one approved [15].

Note that with DSHC (farnesane), HEFA (hydro processed esters and fatty acids) and BtL (biomass to liquid), there are now three conversion technologies available for the production of sustainable alternative fuels, providing substantial progress regarding sustainability and $\mathrm{CO}_{2}$ emissions.
Further future candidates to jet fuel, such as renewable synthetic jet fuels known as alcohol to jet (ATJ) and sugar to jet (STJ) are discussed and investigated; they are expected to be certified soon by ASTM.

Table 1: Alternative aviation fuels certified

\begin{tabular}{|c|c|c|c|}
\hline $\begin{array}{c}\text { Certified } \\
\text { Alternative } \\
\text { Aviation fuel }\end{array}$ & Year & Blend & Reference \\
\hline $\begin{array}{c}\text { SSJF } \\
\text { Semi synthetic } \\
\text { jet fuel }\end{array}$ & 1998 & $\begin{array}{c}50 \% \mathrm{CtL}- \\
\text { based SPK + } \\
\text { Jet A-1 }\end{array}$ & $\begin{array}{c}\text { Def-Stan 91-91 (UK) } \\
\text { Annexes for Sasol }\end{array}$ \\
\hline $\begin{array}{c}\text { FSJF } \\
\text { Fully synthetic } \\
\text { jet fuel }\end{array}$ & 2008 & $\begin{array}{l}100 \% \text { CtL- } \\
\text { based } \\
\text { kerosene } \\
\text { from SPK \& } \\
\text { aromatics }\end{array}$ & $\begin{array}{c}\text { Def-Stan 91-91 (UK) } \\
\text { Annexes for Sasol }\end{array}$ \\
\hline $\begin{array}{c}\text { FT-SPK } \\
\text { Fischer-Tropsch } \\
\text { Synthetic } \\
\text { paraffinic } \\
\text { kerosene }\end{array}$ & 2009 & $\begin{array}{l}\text { up to } 50 \% \\
\text { in Jet A-1 } \\
\text { Generic } \\
\text { approval } \\
\text { and } \\
\text { certification }\end{array}$ & $\begin{array}{c}\text { ASTM D4054 } \\
\text { standard practices for } \\
\text { qualification and approval of } \\
\text { new aviation turbine fuels } \\
\text { and fuel additives } \\
\text { ASTM D7566 } \\
\text { standard specification for } \\
\text { aviation turbine fuels } \\
\text { containing synthesized } \\
\text { hydrocarbons }\end{array}$ \\
\hline GtL & $\begin{array}{l}\text { Sept } \\
2009\end{array}$ & $\begin{array}{l}\text { up to } 50 \% \\
\text { in Jet A-1 }\end{array}$ & $\begin{array}{c}\text { ASTM D7566 } \\
\text { revised release } \\
\text { includes 50\% GTL } \\
\text { Kerosene }\end{array}$ \\
\hline $\begin{array}{c}\text { HEFA } \\
\text { hydro-processed } \\
\text { esters and fatty } \\
\text { acids }\end{array}$ & $\begin{array}{l}\text { July } \\
2011\end{array}$ & $\begin{array}{l}\text { up to } 50 \% \\
\text { in Jet A-1 }\end{array}$ & $\begin{array}{l}\text { ASTM D7566 } \\
\text { revised release } \\
\text { includes HEFA }\end{array}$ \\
\hline $\begin{array}{l}\text { SIP Synthesized } \\
\text { Iso-Paraffins }\end{array}$ & $\begin{array}{l}\text { July } \\
2014\end{array}$ & $\begin{array}{l}\text { up to } 10 \% \\
\text { in Jet A-1 }\end{array}$ & ASTM D7566 \\
\hline $\begin{array}{c}\text { DSHC } \\
\text { (Farnesane) }\end{array}$ & & $\begin{array}{l}\text { produced } \\
\text { from hydro } \\
\text { processed } \\
\text { fermented } \\
\text { sugars }\end{array}$ & $\begin{array}{c}\text { revised release } \\
\text { includes synthesized Iso- } \\
\text { Paraffins (SIP) } \\
\text { farnesane } \\
\text { (Amyris/Total) }\end{array}$ \\
\hline
\end{tabular}

It should be noted that within the production process of synthetic jet fuels, hydrocracking e.g. of vegetable oil and hydrogenation are part of the overall process chain [35-36]. An interesting feature of modern hydrogenation processes is the possibility of influencing the size of the carbon chain as well as the chemical family of the products (branched or long-chained paraffines). This has an important influence on the physical properties of the resulting products such as cetane index and cold flow properties. Thus, a science based investigation of this interaction is desirable.

\subsection{Composition of aviation jet fuels}

Typical kerosene from crude oil (Jet A-1) consists of a large variety of different species belonging to four chemical families: (i) long-chained unbranched alkanes (n-alkanes or $n$-paraffins), (ii) long-chained, branched alkanes (iso-alkanes or iso-paraffins) (iii) cyclo-alkanes (naphthenes or cyclo-paraffins) and (iv) aromatics 
(Fig. 2). Note that fuel additives may also be present, such as antioxidants, antistatic agents, and metal deactivators [10-11].

A single kerosene, however does not exist because its detailed composition is always dependent on the origin of the crude-oil and its processing; furthermore, it varies over time. No comprehensive knowledge has been achieved with respect to how certain families of compounds or single species within Jet A-1 might affect specific properties (chemical and physical) of the fuel and what might be their impact on engine performance and emissions, the aircraft systems and/or ground handling and safety.

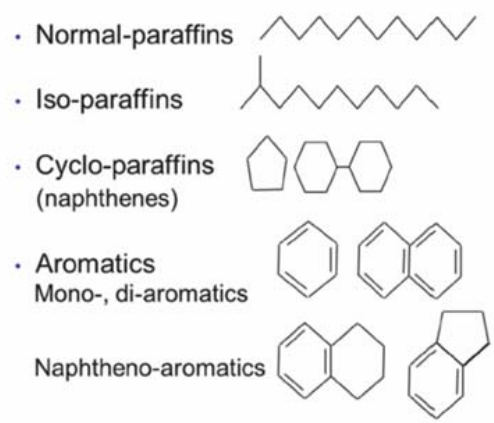

Fig. 2: Chemical families present in Jet A-1

A detailed knowledge about the amount and type of chemical components can be obtained by applying a GC/MS or a GC/GC/MS analysis, as depicted exemplarily in Fig. 3 . The composition of alternative aviation fuels is similar to the one of Jet A-1 - only hydrocarbons $[3,38])$. However, the size distribution of hydrocarbons, and their chemical family might differ considerably.

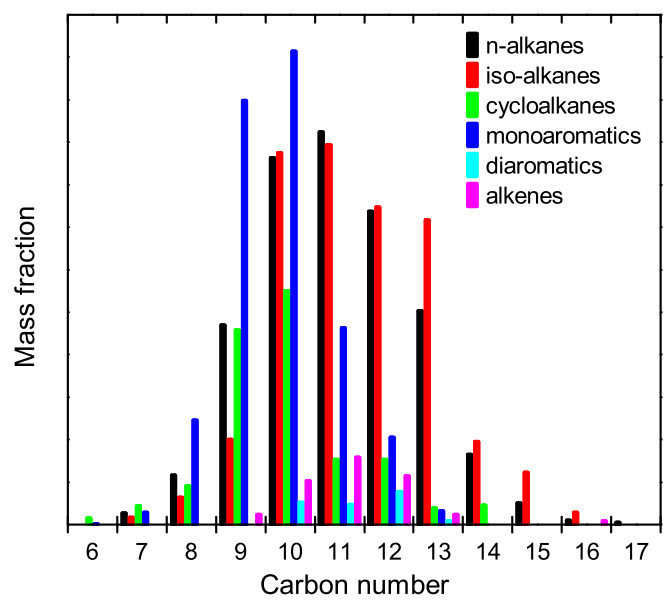

Fig. 3: Chemical composition of Jet A-1, Stuttgart airport [37]

For example, a GtL, which is allowed to be blended up to $50 \%$ with Jet A-1, is a mixture of only three chemical families, without any aromatics [38]. This affects the emission behavior leading to a considerably reduced number of particulates; i.e. having a better performance with respect to the environment compared to a crude-oil kerosene [26].

Furthermore, the recently approved DSHC process leads to a single renewable molecular species that is allowed to blend with Jet A-1 up to $10 \%$. Farnesane is a long-chained, branched alkane (2,6,10-trimethyldodecane, $\mathrm{C}_{15} \mathrm{H}_{32}$ ) resulting from the conversion of the fermentation products of $\mathrm{C} 5$ - and C6-sugars originating from different feedstock by yeasts [39].

Now, with the production and existence of several alternative jet fuels of a composition significantly different to the one of petroleum-based Jet A-1, the question is on how the chemical nature of the fuel will affect its suitability (safety) and performance (with combustion being a major part of).

A profound knowledge is needed, with respect to chemical, physical, and thermo-physical fuel properties and with respect to the combustion process occurring in the combustor under highly turbulent conditions.

\section{Approach of present work}

The chemical composition of any fuel determines the thermo-physical and thermo-chemical properties, and thus, the behavior as well as the combustion of the fuel. When formulating a new aviation jet fuel, the effect of individual components needs to be carefully investigated to exclude any shortcomings or problems with respect to performance and safety issues.

The aim of the present work is to elaborate the interaction between the composition of a jet fuel and its molecular properties - thermo-chemical and thermophysical.

To ensure operability and the safety of flight, some of these properties have strong limits as specified in ASTM D1655-14a [10], whereas some of them have typical values like autoignition and flammability limit. For example, the freezing point has to be below $-40^{\circ} \mathrm{C}$ (for Jet A) in order to keep high altitude flight capabilities; the thermal stability must be sufficiently high in order to preserve engine cooling capability and prevent coking at the same time; the energy density will tailor the aircraft mission range, e.g. the specific energy density impacts on aircraft take-off weight, the volumetric density on aircraft range.

To understand the contribution of the different fuel components, selected major properties (see Table 2) were gathered from literature [40-44] and plotted vs. total number of carbon atoms, for different chemical families (see Figs. 6-13b).

By using appropriate mixing rules, multicomponent fuel models can be formed that describe accurately the properties of real fuels.

Thus, in the present work, two aspects are addressed: (i) contributing to a model-based test procedure of fuel candidates, within the approval process of a synthetic jet fuel, with respect to the characterization of the bulk properties; (ii) contributing to the identification of components of a promising future jet fuel, with pre- 
selected and pre-defined properties, as a more scientific way of designing an innovative synthetic fuel, by exploiting the dependencies of molecular properties vs. the number of carbon atoms. This strategy will enable, in future, a more sophisticated and more reliable description and prediction of the turbulent combustion of a jet fuel occurring in a gas turbine.

Table 2: Selected major molecular properties for hydrocarbons, with different total numbers of carbon atoms, for different families

\begin{tabular}{|c|c|c|c|c|}
\hline Molecule & N-alkane & Iso-alkane & $\begin{array}{l}\text { Cyclo- } \\
\text { alkane }\end{array}$ & Aromatic \\
\hline \multicolumn{5}{|l|}{ Property } \\
\hline Specific energy & C5-C20 & C4-C12 & C5-C10 & C6-C22 \\
\hline $\begin{array}{l}\text { Autoignition } \\
\text { temperature }\end{array}$ & C5-C20 & C4-C12 & C5-C10 & C6-C10 \\
\hline $\begin{array}{l}\text { Flammability } \\
\text { limits }\end{array}$ & C5-C20 & C4-C12 & C5-C10 & C6-C22 \\
\hline Boiling point & C5-C20 & C4-C12 & C5-C10 & C6-C22 \\
\hline Melting point & C5-C20 & C4-C12 & C5-C10 & C6-C22 \\
\hline Cetane number & C5-C20 & C4-C12 & C5-C10 & C6-C22 \\
\hline $\begin{array}{l}\text { Density } \\
@ 15^{\circ} \mathrm{C}\end{array}$ & C4-C20 & C4-C16 & C5-C20 & C6-C22 \\
\hline
\end{tabular}

\section{Combustion of aviation jet fuels}

Combustion in a jet engine is occurring under turbulent conditions, by using a liquid fuel. To be able to describe efficiently this process, the interactions between atomization, evaporation, and placement of the fuel and its (turbulent) combustion, need to be investigated in detail. In this context, numerical simulations are of high interest towards a more detailed understanding what is occurring during combustion under these highly turbulent condition.

This implies, however, the need of several models' ability to describe comprehensively the effects with respect to fuel placement: (i) fuel's atomization; (ii) fuel's evaporation; and (iii) fuel's combustion (chemical properties). Thermo-physical properties are dominating the effects (i) to (ii), chemical properties effect (iii). In addition, chemical kinetic reaction models are one of the essentials among a variety of models and methods used in CFD simulations [26].

For evaluation and verification of the models, relevant investigations, over a relevant parameter range (temperature, pressures fuel composition, and fuel-air ratio), need to be performed to guarantee the accuracy of the models.

Once done, such models may be used for studying the potential of a fuel candidate to serve as an alternative aviation fuel or a detailed and/or optimized design of a combustion chamber using CFD simulations. For details, refer to [26].

In the present work, these effects are studied in dependence as a function of the fuel - amount, size distribution of hydrocarbon molecules, and chemical family. This strategy is considered a major step towards the approach of virtual prototyping of new fuel compositions and jet engine combustors.

\subsection{Thermo-physical properties}

Thermo-physical properties determine significantly the fuel preparation process and furthermore some combustor performance issues as ignition, altitude relight, and lean blowout [27].

In the context of this work, special importance is placed in conserving the information about the fuel composition over the processes occurring in combustion chambers. This allows to determine the sensitivity of the various processes on changes in the liquid fuel composition. For this reason, advanced methods for the fuel modeling are used based on continuous thermodynamics. In Continuous Thermodynamic Models (CTM), the different chemical families present in the fuel are described with appropriate distribution functions, e.g. Gamma PDF. This allows to save computational time and, at the same time, preserving the major details of the complex composition.

Applications of CTM to describe the effect of alternative aviation fuel have been demonstrated [18] by using phenomenological models to estimate the effect of different fuel composition on the atomization and in CFD simulations of a jet engine combustor using different alternative aviation fuels [45].

\subsection{Combustion properties}

Due to its complex composition, the combustion of kerosene is modeled by introducing so-called surrogates or model fuels. A surrogate is composed of several hydrocarbons selected from those chemical families which represent the major components and their fraction in a given fuel $[17,26,46]$.

A surrogate can be built such that it has physical and chemical properties similar to those of the real jet fuel. Several formulas for a surrogate exist, with - depending on the objective - 3-7 hydrocarbons present, to describe the combustion properties of practical blends, see e.g. [17, 19-21, 46-47].

Surrogates are of high interest since they allow studying the effect of chemical composition on the fuel's properties and on the combustion process [19-21], in particular in CFD simulations.

Within the present work, the relationship of the combustion properties of interest with the molecular structure is re-visited, with the help of detailed chemicalkinetic reaction mechanisms, which can comprise more than about 2000 species and 8000 reactions [21]. For selected single components used as a typical representative for the four chemical families, results are shown for burning velocities (Fig. 4) and for ignition delay time measurements (Fig. 5).

Concerning the fuel's combustion, detailed knowledge on major combustion properties e.g. ignition delay time (safety), laminar flame speed (stability), and emission pattern (pollutants) is required. This knowledge allows avoiding operating conditions where flashback or auto 
ignition may cause a severe damage of the burner or the combustion chamber; for details, refer to [17-21, 25-26].

These properties are usually gathered from experiments. However, measurements cannot always be performed, for several reasons, e.g. non-availability on requisite amount of fuel of interest; parameter field of interest not accessible; time and cost constraints on number of experiments to be performed.

To predict combustion properties of a fuel, a detailed reaction model is required [17, 19-21, 45]. Through such models, combustion properties of ignition delay times, flame speeds can be predicted as shown in Figs. 4 and 5 . Furthermore, such models can be used, once reduced with respect to number of species, and thus, of reactions also, for CFD calculations.

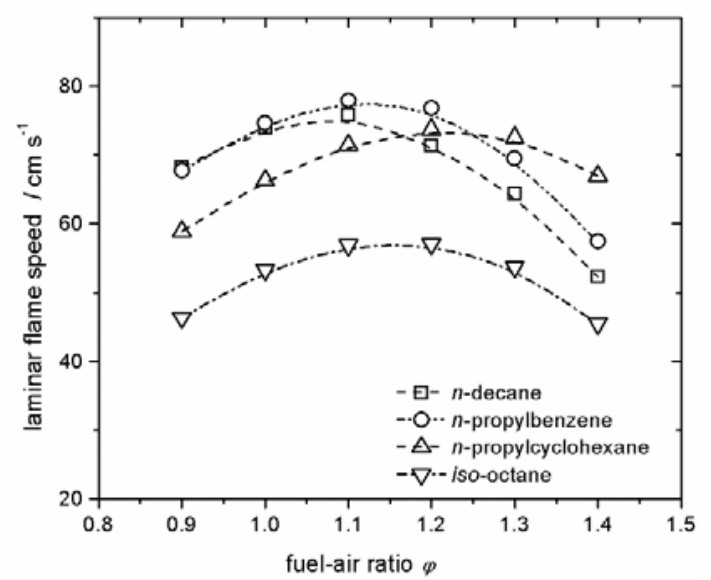

Fig. 4: Predicted laminar flame speed of typical components of a jet fuel. Calculated at a preheat temperature of $T_{0}=473 \mathrm{~K}$ at ambient pressure [19]

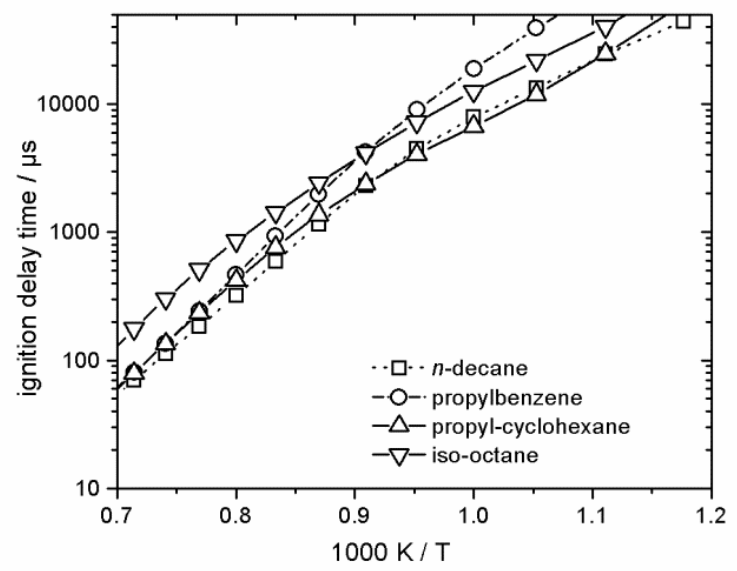

Fig. 5: Predicted ignition delay times of typical components of a jet fuel. Calculated at constant pressure for mixtures in air, at $\varphi=1.0$ and $p=16$ bar, diluted in $\mathrm{N}_{2}(1: 2)$ [20]

\section{Selected molecular properties}

As pointed out above, the detailed composition of alternative aviation fuels may differ considerable, with respect to each other and to Jet A-1, in terms of number of carbon atoms within a molecule and the chemical family. Selected major fuel properties (see Table 2) will be given for the chemical families, as a function of carbon number of a molecule. These properties were selected for their importance with respect to major sub-processes of the turbulent combustion of the fuel in an aero engine. The data shown in Figs. 6-12b were extracted from the DIPPR-801 database [40].

\subsection{Specific energy}

The specific energy is a key fuel performance property. The energy density will tailor the aircraft mission range: the specific energy density impacts on aircraft take-off weight, and the volumetric density impacts on aircraft range.

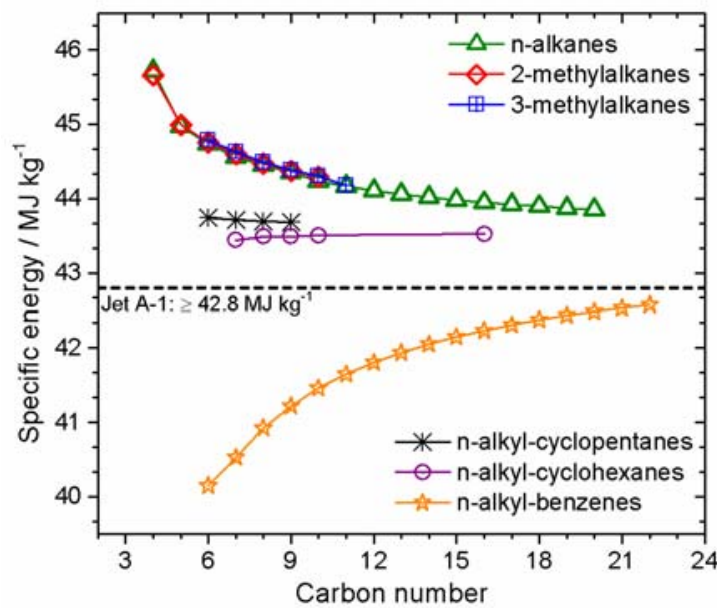

Fig. 6: Plot of specific energy as a function of total number of carbon atoms, for different chemical families. Data taken from [40]

In Fig. 6, the specific energy of a few hydrocarbons present in jet fuels is plotted against carbon number. For clarity, the plots are separated based on their molecular structure. As an example, $n$-alkanes and iso-alkanes (e.g. methylalkanes) have nearly similar energy content; whereas with an increase in the branching, as for alkylcycloalkanes, the energy content increases. Aromatics, e.g. single ring alkyl-benzenes, have much lower energy content. In addition, the higher the total number of carbon atoms, the more energy is available, until a plateau is reached, starting from C10.

\subsection{Autoignition temperature}

Autoignition, not included in ASTM D1655-14a, is the characteristic property of the fuel which supplies information on the lowest temperature under which a fuel may ignite spontaneously in a normal atmosphere without an external source of ignition.

The autoignition temperature is related to ground handling and safety aspects; its determination is part of 
the fuel's properties to be determined within the fuel's specification.

The autoignition of a fuel is largely controlled by the combustion chemistry of the fuel hydrocarbons at given temperature. Therefore, the autoignition temperatures are dependent on the molecular structure of the fuel. Their values are higher for branched chain isomers than for straight chain ones. Generally, within a given structural group, the autoignition temperature (AT) usually decreases with increase in chain length.

Figure 7 shows autoignition for various molecules, including the typical value for Jet A-1. For a given carbon number, branched chains (iso-alkanes, e.g. methylalkanes) have a higher autoignition temperature than straight chains ( $n$-alkanes); similarly, aromatics (alkyl-benzenes) have higher AT values than cycloalkanes. Note that the tendency of autoignition for a carbon number with a branching molecular structure is more complex as it depends on the reactivity of each molecule. Therefore, a generalization on how the value of autoignition will vary, is difficult.

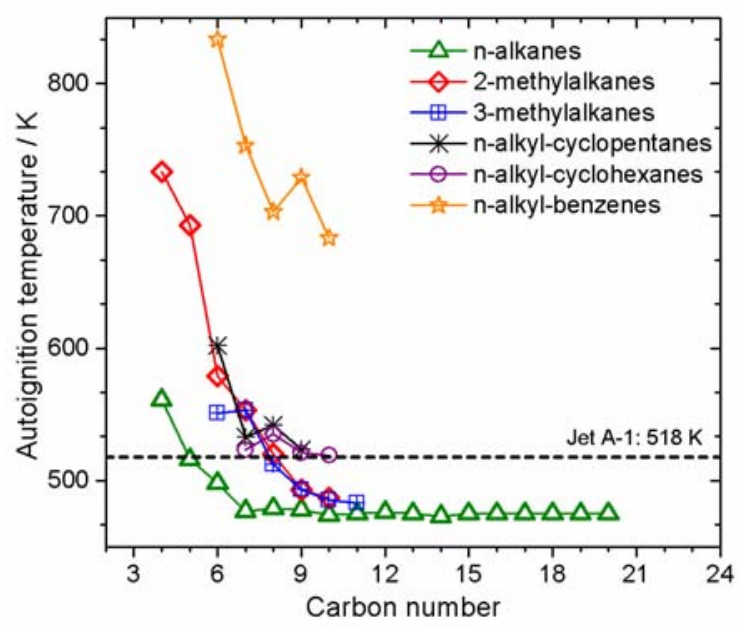

Fig. 7: Plot of autoignition temperature as a function of the total number of carbon atoms, for several chemical families. Data taken from [40]

\subsection{Flammability limit}

The flammability limits of a particular fuel provide fundamental consideration of safety during its storage and processing. It is important for determining the safety range of uncontrolled explosion/combustion. Hence, this property is part of the bulk properties to be determined within the fuel's specification procedure.

The lower and upper flammability limits are determined in percentage volume or in temperature at $25^{\circ} \mathrm{C}$ and atmospheric condition and supplies information on fuel concentration limit outside which fuel does not ignite. The flammability limits of a given fuel depend on various aspects of the measurements such as apparatus geometry, ignition source strength, degree of mixing, concentration of oxygen, and diluents [41].
The flammability limits are nearly independent of the fuel's molecular structure. For example (Fig. 8), for $n$-alkanes, the lower limit decreases with carbon number from C7, to nearly constant for higher carbon numbers. The same is the case with iso-alkanes, with a minor influence of: (i) degree of branching in the molecule; (ii) position of the alkyl group along the main hydrocarbon, and (iii) cis- or trans-structural orientation.

The flammability limit of cycloalkanes and aromatics differ considerably in terms of absolute value compared to $n$ - and iso-alkanes.

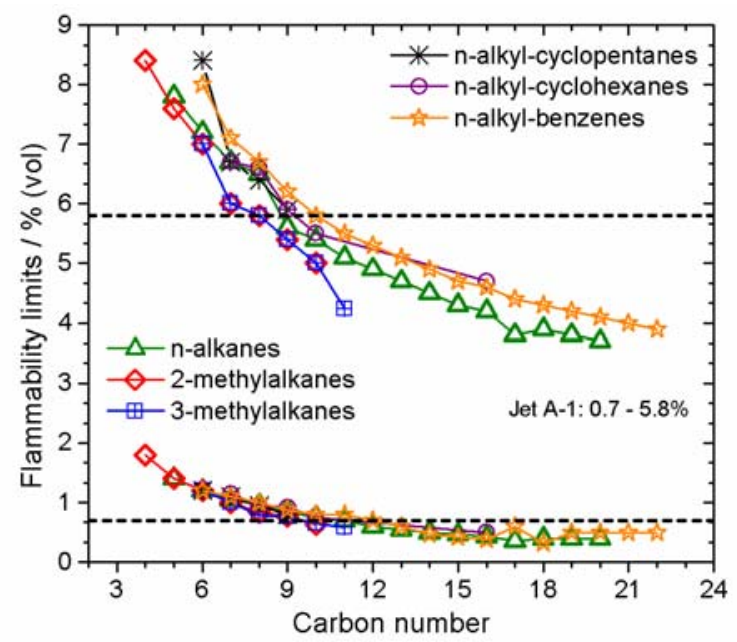

Fig. 8: Plot of flammability limit as a function of total number of carbon atoms, for several chemical families. Data taken from [40]; Jet A-1 [10]

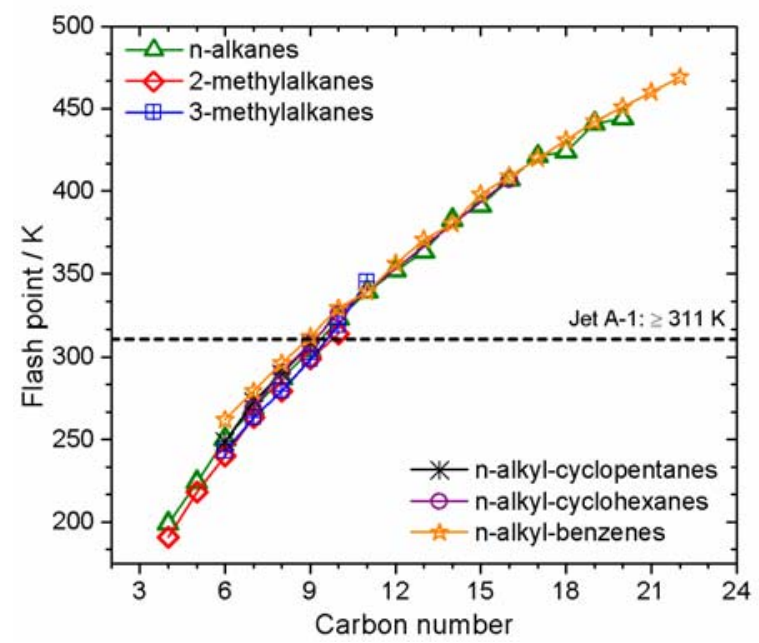

Fig. 9: Plot of flash point as a function of total number of carbon atoms, for several chemical families. Data taken from [40]; Jet A-1 [10]

\subsection{Flash point}

Flash point indicates the combustibility of a liquid to vapor. The flash point is measured by heating a liquid to a certain temperature and the vaporized liquid is subjected to the ignition source. Below flash point, the liquid is not 
sufficiently vaporized to support combustion. It is considered important characteristic temperature of liquids for storage and handling of the fuel above which handling and storage is hazardous.

The flash point at given carbon number shows very small variation (Fig. 9). In general, the flash point increases with increase in carbon number. The increased flash point implies lower combustion hazard of a liquid.

\subsection{Boiling point}

Boiling point is the temperature at which the vapor pressure of the liquid becomes sufficient to overcome atmospheric pressure. The higher the vapor pressure of a liquid at a given temperature, the lower the boiling point of the liquid.

This is a fundamental property representing the evaporation tendencies of the liquid aviation fuel.

The boiling point of a fuel increases with an increase in carbon number, as shown in Fig. 10; however, it is independent of the molecular structure of the fuel, for a given carbon number. The boiling point of $n$-alkanes (triangles) is higher because of stronger molecular bonding owing to large intermolecular forces. Therefore, longer chain alkanes have higher boiling points compared to smaller alkanes. For comparison, the 10 (vol.)\% evaporated temperature, $\mathrm{T}_{10}$, as well as the final temperature, $T_{f}$, are given for Jet A-1; these data are often used to characterize its volatility and distillation characteristics.

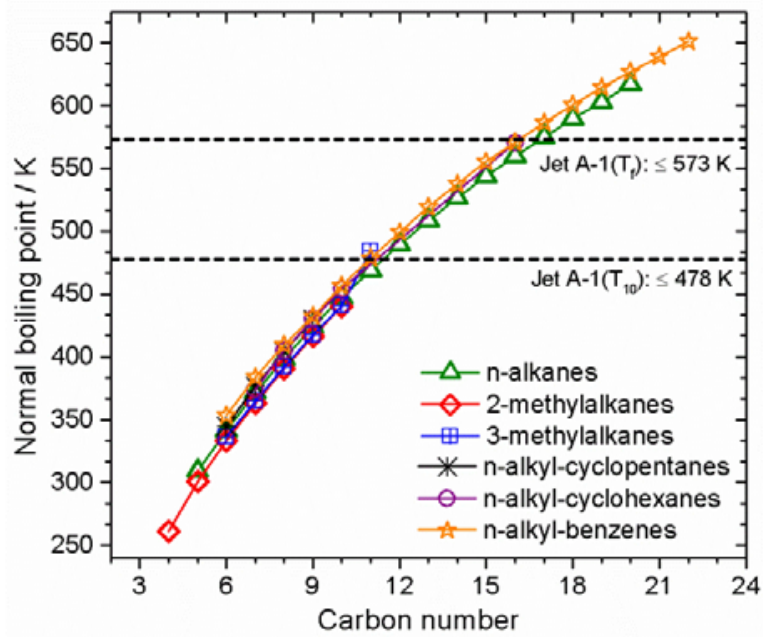

Fig. 10: Plot of boiling point as a function of total number of carbon atoms, for several chemical families. Data taken from [40]; Jet A-1 [10]

\subsection{Melting point}

Melting point as well as freezing point are important properties which assure fluidity of fuel. For aviation fuel, the operating condition at higher altitudes where very low temperatures prevail, the freezing point of the fuel must be as low as $-47^{\circ} \mathrm{C}$ for Jet A-1, in order to ensure flow of fuel through the filter screen to the engines, even at cruise conditions of inter-continental flights (high altitude flight capabilities).

In the present study, based on availability, we have plotted melting point instead of freezing point which is the reverse physical process depicted as negative values. The melting and freezing point temperatures are practically the same or less than up to about $1{ }^{\circ} \mathrm{C}$ difference.

The melting point of different hydrocarbon fuels generally increases with carbon number, as shown in Fig. 11a. This, however, is strongly influenced by the molecular structure of the fuel.

The fuel with molecules with more complex branching structures would have different melting point for same carbon number. For example, Fig. 11b shows the melting point of several dimethyl hexane isomers. Considering the structure of three isomers (red symbols), the 2,5-dimethyl hexane is a more compact and symmetrical molecule which tend to have a higher melting point compared to the other two isomers. In general, the melting point of $n$-alkanes is highest among the hydrocarbons presented here.

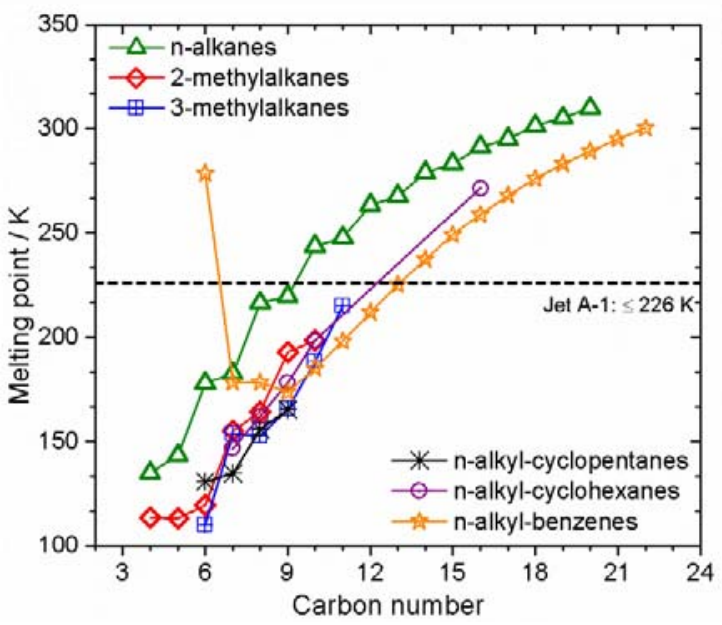

Fig. 11a: Plot of melting point as a function of total number of carbon atoms, for several chemical families. Data taken from [40]; Jet A-1 [10]

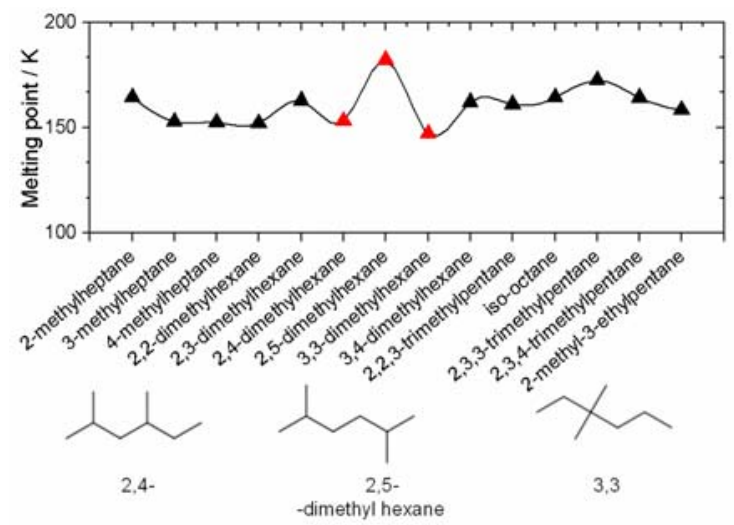

Fig. 11b: Plot of melting point of several iso-alkanes. Data taken from [40] 


\subsection{Cetane number}

The cetane number measures the fuel quality through its ability to ignite; it is related to the fuels ignition delay time. The cetane number is based on a reference scale, with 1-hexadecene commonly known as cetene as reference fuel. Fuels with a higher cetane number will have lower ignition delay times.

The fuel's molecular structure is important for the cetane number because a stable molecular structure requires higher temperature and pressure conditions to ignite; hence, they have lower cetane number.

Usually, the cetane numbers are derived for fuels related to compression engines rather than turbine engines. However, blends of alternative jet fuels with conventional jet fuel are also studied [48-49]. Derived cetane numbers (DCN) of 60 have been recently reported for most of the alternative fuels tested, with the reported DCN for Jet A of 49.35 much lower [48]. The difference is likely due to variation in normal-to-branched alkane ratio in Jet A-1 compared to alternative fuels which have more simpler $n$-alkanes components compared to complex iso-alkanes and aromatics usually present in Jet A-1.

The cetane number for several fuels is shown in Fig. 12. With increase in carbon number, the cetane number increases. In addition, for a given carbon number, the cetane numbers of iso-alkanes are lower than those of $n$-alkanes due to their lesser reactivity.

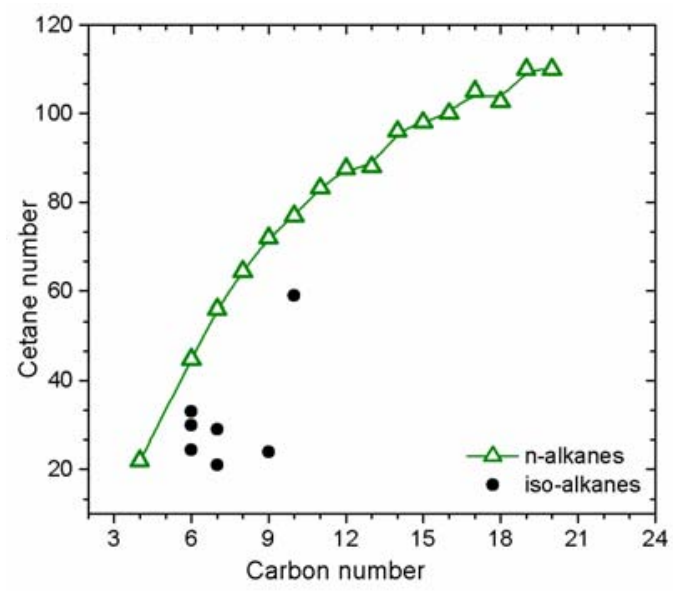

Fig. 12: Plot of cetane number as a function of total number of carbon atoms, for two chemical families. Data taken from [40]. Data for iso-alkanes shown are for: 2-,3-methylpentane, 2,2-dimethylbutane, 2,3-, 2,4-dimethylpentane, 2,2,5-trimethylhexane, 2,2dimethyloctane

\subsection{Density}

The liquid density is an important parameter for aircraft range, fuel metering, and for the fuel preparation process. Due to its importance, it is specified in the aviation turbine fuel specification (ASTM D 1655) with a required range of (775-840) $\mathrm{kg} \mathrm{m}^{-3}$. In Fig. 13a, the contributions of potential fuel families present in jet fuels are shown in comparison with the specification limits. For reaching the specification target, a significant amount of long chain (>C15) $n$ - or iso-alkanes or cycloalkanes and aromatics are required.

Furthermore, to demonstrate that new fuel candidates are "fit-for-purpose", in the approval processes of new turbine fuels (ASTM D 4054), the density is one of the bulk physical and performance properties that is tested and compared with experience values represented by minimum and maximum values from the CRC world fuel survey [44].

To show the application of the fuel models for selecting appropriate fuel candidates, the density of Jet A-1 is computed based on its composition. First, the density relationships of the single compounds present in the fuel (Fig. 3) are used; then, linear mixing rules are applied, to compute the mixture properties. Figure 13b shows the evolution of the fuel density with temperature is within the minimum and maximum values gathered from the CRC world fuel survey for Jet A-1 [44].

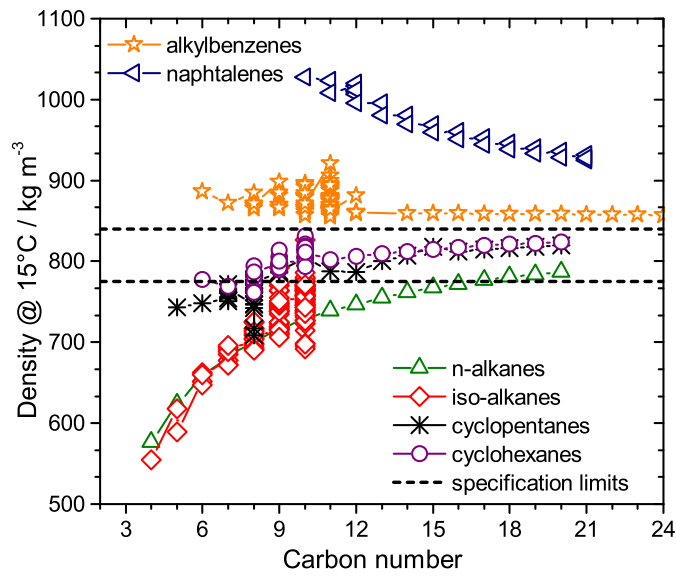

Fig. 13a: Plot of density as a function of total number of carbon atoms, for several chemical families. Data taken from [42-43]

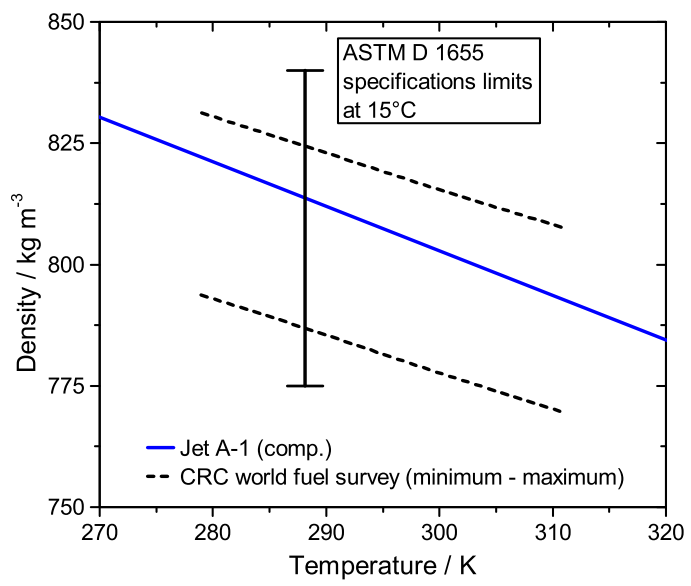

Fig. 13b: Plot of computed Jet A-1 density based on the composition shown in Fig. 3 as a function of temperature compared to experience values [44] 


\section{Summary and conclusions}

Presently, the aircraft industry is looking for the identification and evaluation of alternative aviation fuels, i.e. non-crude oil based kerosene, with a preference on sustainable fuels. A wide range of possible fuel candidates and fuel blends are discussed. Producing a new synthetic jet fuel offers the chance of obtaining a fuel with better performance compared to Jet A-1. The composition of alternative aviation fuels might differ considerably from one another and to Jet A-1, in terms of amount and type of hydrocarbons (different chemical families, molecular size). However, presently, it is an open question how the chemical nature of e.g. a fuel or a fuel candidate will affect its suitability and performance.

For these reasons, selected properties of the components of the four chemical families a jet fuel might be comprised of were considered. The effects considered comprise thermo-physical (fuel placement) and thermochemical properties (fuel's combustion such as autoignition and flame speed). It was shown for many of the parameters considered that the structure-property relationships of the single components are determined by chain length, complexity of branching structure (degree of branching, location of alkyl group, structural orientation) and reactivity.

Combined efforts of computational fluid dynamics modeling and experimental characterization are required to build a comprehensive knowledge of synthetic jet fuel properties. With a detailed understanding of the effect of fuel composition on combustor relevant processes a more efficient and optimized use of synthetic fuels in aeroengines may be achieved. Furthermore, to model multicomponent fuel properties, mixing rules capturing the linear or non-linear interaction between the molecules have to be evaluated carefully.

The ultimate goal is to model the interdependency from fuel composition, to fuel properties, and, finally, to combustion performance, of alternative fuels including biofuels as well as candidate biofuels.

Thus, the road will be paved for contributing to developing a more general and more science based tool to investigate in an efficient way if a new fuel candidate may meet the fuel specifications.

Acknowledgements The financial support of the Federal Ministry for Economic Affairs and Energy (Germany) within InnoTreib is gratefully acknowledged. The authors thank P. Le Clercq for fruitful discussions and M. Estellar for assistance in gathering properties values.

\section{References}

1. Intergovernmental Panel on Climate Change (IPCC) in: Mitigation of Climate Change. Contribution of Working Group III to the Fifth Assessment Report of the IPCC.
O. Edenhofer et al. (eds.), Cambridge University Press, Cambridge, United Kingdom and New York, NY, USA, http://www.ipcc.ch/report/ar5/wg3/ (2014)

2. Kohse-Höinghaus K., Oßwald P., Cool T.A., Kasper T., Hansen N., Qi F., Westbrook C.K., Westmoreland P.R.: Biofuel Combustion Chemistry: From Ethanol to Biodiesel. Angew. Chem. Int. Ed. 49, 3572-3597 (2010)

3. http://www.caafi.org/

4. Advisory Council on Aeronautics Research in Europe (ACARE), "Acare addendum to the strategic research agenda",

http://www.acare4europe.com/docs/ACARE_2008_Adden dum.pdf; (2008)

5. ALFA-BIRD: Alternative Fuels and Biofuels for Aircraft, EUFP7/2007-2013, grant agreement no 213266; coordinator: EU-VRi, (Germany); http://www.alfa-bird.euvri.eu

6. SWAFEA: Sustainable Way for Alternative Fuels and Energy for Aviation, EU, DG-TREN, final report, http://www.icao.int/environmentalprotection/GFAAF/Documents/SW_WP9_D.9.1\%20Final \%20report_released\%20July2011.pdf

7. International Air Transport Association, http://www.iata.org/whatwedo/Documents/economics/Indu stry-Outlook-Jun2012.pdf

8. http://www.aireg.de

9. burn-FAIR, LuFO-IV http://presse.lufthansa.com/en/newsreleases/singleview/archive/2010/november/29/article/1828 .html (2011)

10. ASTM Standard D1655, www.astm.org

11. http://www.dstan.mod.uk/

12. http://aviationbenefits.org/environmentalefficiency/sustainable-fuels/passenger-biofuel-flights/

13. FT-fuels approved, announcement, (2011), http://www.astmnewsroom.org/default.aspx?pageid=1895

14. HEFA approved, announcement, (2011) http://www.astmnewsroom.org/default.aspx?pageid=2524

15. SIP-fuels approved, announcement, (2014), http://www.astmnewsroom.org/default.aspx?pageid=3463

16. Wahl C., Aigner M.: Aircraft Gas Turbine Soot Emission Tests under Technical Relevant Conditions in an Altitude Test Facility and Validation of Soot Measurement Technique. GT2003-38797, Proc. ASME Turbo Expo 2003, Atlanta, USA (2003)

17. Steil U., Braun-Unkhoff M., Frank P., Aigner M.: An experimental and modelling study on the autoignition of kerosene and surrogate fuel mixture. AIAA-2008-0973, Proc. 46th AIAA Aerospace Sciences Meeting and Exhibit, Reno, USA (2008)

18. Le Clercq P., Aigner M.: Impact of Alternative Fuels Physical Properties on Combustor Performance. ICLASS 2009, $11^{\text {th }}$ Triennial Internat. Annual Conference on Liquid Atomization and Spray Systems, Vail, USA (2009)

19. Kick Th, Herbst J., Kathrotia T., Marquetand J., BraunUnkhoff M., Naumann C., Riedel U.: An Experimental and Modeling Study of Burning Velocities of Possible Future Synthetic Jet Fuels. Energy 43(1), 111-123 (2012)

20. Mzé Ahmed A., Dagaut P., Hadj-Ali K., Dayma G., Kick Th., Herbst J., Kathrotia T., Braun-Unkhoff M., Herzler, J. Naumann C., Riedel U.: Oxidation of a Coal-to-Liquid Synthetic Jet Fuel: Experimental and Chemical Kinetic Modeling Study. Energy Fuels 26(10), 6070-6079 (2012)

21. Dagaut P., Karsenty F., Dayma G., Diévart P., Hadj-Ali K., Mzé-Ahmed A., Braun-Unkhoff M., Herzler J., Kathrotia T., Kick Th., Naumann C., Riedel U., Thomas L.: Experimental and Detailed Kinetic Model for the Oxidation 
of a Gas to Liquid (GtL) Jet Fuel. Combust. Flame 161, 835-847 (2014)

22. InnoTreib - Innovative Treibstoffe der Zukunft, Project funded by Bundesministerium für Wirtschaft und Energie, Germany, 2014-2017

23. airbus, sustainable aviation fuels, http://www.airbus.com/innovation/ecoefficiency/operations/alternative-fuels/

24. Braun-Unkhoff M., Le Clercq P., Aigner M.: Alternative Fuels and Biofuels for Aircraft Development. Proc. of 17th European Biomass Conference and Exhibition, Hamburg, Germany (2009)

25. Blakey S., Rye L., Wilson C.W.: Aviation gas turbine alternative fuels: A review. Proc. Comb. Inst. 33, 28632885 (2011)

26. Braun-Unkhoff M., Riedel U.: Alternative Fuels in Aviation. CEAS Aeronautical Journal 6(1), 83-93 (2015) DOI: 10.1007/s13272-014-0131-2. ISSN 1869-5590

27. Edwards C., Moses C., Dryer F.L.: Evaluation of Combustion Performance of Alternative Aviation Fuels. 46th AIAA/ASME/SAE/ASEE Joint Propulsion Conference \& Exhibit, Nashville, USA, AIAA 2010-7155 (2010)

28. http://www.caafi.org/information/pdf/Path_to_Aviation_Al ternative_Fuel_Readiness_May_2013.pdf (2013)

29. http://www.caafi.org/information/fuelreadinesstools.html.

30. http://www.caafi.org/information/pdf/FeedstockReadinessL evel_posted_2011_12.pdf

31. Roadmaps, http://www.caafi.org/information/roadmaps.html.

32. Mosbach T., Burger V., Gunasekaran B.: Fuel Influence on Targeted Gas Turbine Combustion Properties: Part I Detailed Diagnostics. Proc. ASME Turbo Expo 2014, Düsseldorf, Germany, GT2014-25075 (2014)

33. Burger V., Yates A., Mosbach T., Gunasekaran B.: Fuel Influence on Targeted Gas Turbine Combustion Properties: Part II - Detailed Results. 2014, Düsseldorf, Germany, GT2014-25105 (2014)

34. Passenger biofuel flights, http://aviationbenefits.org/environmentalefficiency/sustainable-fuels/passenger-biofuel-flights/

35. http://www.nesteoil.com/default.asp?path=1,41,11991,122 43,17555, Neste Oil

36. http://www.uop.com/honeywells-uop-renewable-jet-fueltechnology-military-testing-certification/ , UOP Honeywell

37. Wahl C., Kapernaum M.: EU FP5 G4RD-CT-00075. Final Report, DLR, Stuttgart, Germany (2003)

38. Moses C.A.: Comparison of Semi-Synthetic Jet Fuels. CRC Project No. AV-2-04a. Contract. Coordinating Research Council, Inc. (2008)

39. Farnesane as jet fuel component approval, press release http://www.aireg.de/en/press-releases/333-milestone-forsustainable-aviation-innovative-fuel-gains-approval.html

40. American Institute of Chemical Engineers (AIChE), Evaluated Process Design Data, Public Release Documentation, Design Institute for Physical Properties (DIPPR), Project 801 (2006)

41. Sheldon M.: A study of the flammability limits of gases and vapors. Fire Prev. 174, 23-31 (1984).

42. Poling B.E., Prausnitz J.M., O'Connell J.P.: The Properties of Gases and Liquids. 5 ed. McGraw-Hill Professional (2000)

43. Frenkel M., Chirico R.D., Diky V., Muzny C.D., Lemmon E.W, Yan X., Dong Q.: NIST Standard Reference Database 103a, NIST ThermoData Engine, Version 2.1; Standard Reference Data. Gaithersburg, MD (USA), National Institute of Standards and Technology - NIST (2005)
44. Hadaller O.J., Johnson J.M.: World Fuel Sampling Program. CRC Report No. 647, Coordinating Research Council, Inc., Alpharetta, GA $30022 \quad$ (2006) http://www.crcao.com/publications/aviation/index.html

45. Le Clercq P., Di Domenico M., Rachner M., Ivanova E., Aigner M.: Impact of Fischer-Tropsch fuels on aero-engine combustion performance. 48th AIAA Aerospace Sciences Meeting, Orlando, USA (2010)

46. Dagaut P., Cathonnet M.: The ignition, oxidation, and combustion of kerosene: A review of experimental and kinetic modeling. Prog. Energ. Combust. 32, 48-92 (2006)

47. Slavinskaya N., Riedel U., Saibov E., Kumaran K.: Surrogate Model Design for GTL Kerosene. Proc. 50th AIAA Aerospace Sciences Meeting and Exhibit, Nashville, USA (2012)

48. Hui X, Kumar K, Sung C, Edwards T, Gardner D.: Experimental Studies on the combustion characteristics of alternative jet fuels. Fuel 98, 176-182 (2012)

49. Jeyashekar N, Muzzell P, Sattler E. Hubble N.: Lubricity and derived cetane number measurements of jet fuels, alternative fuels and fuel blends. Interim report TFLRF No. 405, US Army TARDEC fuels and lubricants research facility, San Antonio (2010) 